\title{
Geoprocessamento e sensoriamento remoto aplicados à análise de recursos florestais ${ }^{1}$
}

\author{
Geoprocessing and remote sensing applied to the analysis of forestal resources
}

\author{
Édson Luis Bolfe ${ }^{2}$ Rudiney Soares Pereira ${ }^{3}$ Pedro Roberto de Azambuja Madruga ${ }^{3}$
}

\section{RESUMO}

Este trabalho tem como objetivo apresentar uma proposta metodológica para o levantamento e análise dos recursos florestais dos povoamentos naturais e implantados, obtido através da utilização de técnicas de geoprocessamento e sensoriamento remoto e localizados na carta topográfica $\mathrm{SH}$. 22-Y-A, Cachoeira do Sul, RS. Para tal, utilizaram-se imagens de satélites associadas ao sistema de informações geográficas, processadas por técnicas de classificação digital e funções matemáticas. Dessa forma, realizou-se o levantamento e a quantificação das diferentes bases temáticas. As variáveis e bases temáticas foram obtidas através das imagens de satélite, trabalho de campo, carta topográfica e cruzamentos geoespaciais, obtendo o uso da terra, espécie implantada, área ocupada, além da localização dos povoamentos florestais quanto à declividade, tipo de solo, rede hidrográfica e disponibilidade viária. Assim, essas informações permitiram analisar a situação da cobertura florestal da região de estudo, fornecendo subsídios ao gerenciamento dos recursos florestais e a preservação do meio ambiente.

Palavras-chave: imagem de satélite, classificação digital, recursos florestais.

\section{ABSTRACT}

This study presents a methodology for survey and analysis of the forestal resources of natural and implanted populating located in the topographic leaf SH.22Y-A, Cachoeira do Sul, RS, (Brazil) by using geoprocessing and remote sensing technics. For this purpose, the Geographic Information Systems, associated to satellite images, processed by digital classification and mathematics' functions were used. In so doing data gathering and quantification of different thematic bases of the studied area. Variables and thematic bases eere accomplished the satellite images, assessed in the field and topographic maps and the geospacials crossings obtaining the land use, implanted species, taken area, besides the localization of the forest concerning slope, edaphic, hydrographic and road availability. Thus, these information obtained by comparing these variables, made it possible to analyze the forestal cover of the study area, supplying subsidy to the forestal resources management and the environmental preservation.

Key words: satellite images, digital classification, forest resources.

\section{INTRODUÇÃO}

A utilização de matéria prima de origem florestal aumentou significativamente nas últimas décadas. Como causa dessa demanda, destaca-se o aumento populacional, o crescimento no consumo de celulose e papel, a tecnificação da indústria moveleira e a produção de energia. Porém, são crescentes as restrições impostas pela legislação na exploração florestal. Conforme CÓDIGOFLORESTALBRASILEIRO (1965), são de preservação permanente as florestas e demais formas de vegetação natural situadas ao longo dos rios e de qualquer curso d'água, desde o nível mais alto em faixa marginal cuja largura mínima seja de 30m, assim como nas encostas ou partes destas com declividade superior a $45^{\circ}$, equivalente a $100 \%$.

Dessa forma, as empresas do setor florestal voltaram-se à busca de espécies florestais, que pressupõem alta produtividade em reduzido ciclo e não são previstas na legislação florestal, viabilizado através da implantação de espécies exóticas, principalmente

${ }^{1}$ Fração da Dissertação de Mestrado do primeiro autor, apresentada ao Programa de Pós graduação em Engenharia Agrícola, Universidade Federal de Santa Maria (UFSM).

${ }^{2}$ Engenheiro Florestal, MSc., Pesquisador, Embrapa Tabuleiros Costeiros. Avenida Beira Mar, 3250, 49025-040, Aracaju, SE. E-mail: bolfe@cpatc.embrapa.br. Tel. (+79) 226-1339 / Fax. 226-1369. Autor para correspondência.

${ }^{3}$ Engenheiro Florestal, Doutor, Professor Titular, Departamento de Engenharia Rural, UFSM. 
Eucalyptus sp. e Pinus sp. Esta alternativa porém, não basta para dar suporte à demanda existente, uma vez que tanto as empresas do setor como os órgãos governamentais não possuem informações confiáveis das áreas florestais. Para as empresas manterem sua produção constante e o Governo definir políticas setoriais, os mesmos dependem de projeções as quais invariavelmente se defrontam com a falta de informações. Tornase assim, imprescindível promover a eficiente utilização das áreas de produção florestal como recurso estratégico para abastecer o mercado consumidor e concomitantemente manter o potencial produtivo dos recursos naturais gerados a partir dessas unidades de produção.

Tradicionalmente, o levantamento e a qualificação do potencial de produção florestal não é efetivo, pois demanda elevado fluxo de informações, as quais encontram dificuldade em alocar, detalhar, organizar, interpretar, e principalmente armazenar de forma que garantam um confiável banco de dados. Segundo ASSAD \& SANO (1998), banco de dados é um conjunto de arquivos estruturados de forma a facilitar o acesso a conjuntos de informações que descrevem determinadas entidades do mundo.

Essas informações são possíveis de serem sistematizadas por meio da utilização de técnicas de geoprocessamento e sensoriamento remoto. Conforme TEIXEIRA et al. (1997), geoprocessamento é a tecnologia que abrange o conjunto de procedimentos de entrada, manipulação, armazenamento e análise de dados espacialmente referenciados. SILVA et al. (1998) definem geoprocessamento como um conjunto de procedimentos computacionais, que operando sobre bases de dados geocodificados, executam análises, reformulações e síntese sobre os dados ambientais tornando-os utilizáveis em um sistema de processamento automático integrado ao banco de dados. ASRAR (1989) conceitua o sensoriamento remoto como a aquisição de informações e/ou estado de um alvo por um sensor, sem estar em contato físico com ele. NOVO (1992) define como sendo a tecnologia da utilização conjunta de sensores, equipamentos de processamento e transmissão de dados, aeronaves, espaçonaves, com o objetivo de estudar o ambiente terrestre por meio de registro e análise das interações eletromagnéticas com as substâncias componentes do planeta Terra, em suas mais diferentes manifestações.

A partir dos dados obtidos pelo sensoriamento remoto, torna-se necessário distinguir e identificar as informações existentes sobre a superfície. Esse procedimento é efetuado através do método de classificação digital, que segundo Dutra et al. apud PEREIRA (1995), é constituído basicamente por um alvo, um sistema sensor ou receptor, um sistema e/ou seletor de canais e um algoritmo classificador. Nesse contexto, definiu-se trabalhar com a classificação digital supervisionada pelo método de máxima verossimilhança, na qual o algoritmo de classificação consiste num princípio estatístico paramétrico, considerando as classes envolvidas uma função densidade de probabilidade gaussiana (PEREIRA 1995).

Essas informações permitem planejar e executar ações de cunho técnico, tendo como suporte dados econômicos e operacionais obtidos através da utilização dos Sistemas de Informações Geográficas (SIG). BURROUGH (1989) conceitua SIG como aplicativos constituídos de cinco módulos e, segundo ele, cada módulo é um subsistema que permite as operações de entrada e verificação de dados, armazenamento e gerenciamento de banco de dados, apresentação e saída de dados, transformação de dados e interação com o usuário. Assim, o uso de SIG permite aplicar metodologias diferenciadas visando ao levantamento e planejamento da produção florestal. As unidades de produção florestal da região estudada apresentam diferentes características de implantação, assim, diferem quanto às necessidades de planejamento do manejo. Como exemplos de adversidades silviculturais, destacam-se: o tombamento de maciços florestais devido às condições edáficas, incidência de pragas em diferentes níveis culturais devido à descaracterização natural e as dificuldades de exploração por não observação do relevo e da rede viária.

O objetivo do trabalho foi aplicar uma metodologia baseada em técnicas de geoprocessamento e sensoriamento remoto, visando a análise da distribuição espacial dos recursos florestais abrangidos pela carta topográfica SH. 22-Y-A. As informações levantadas dos povoamentos florestais foram submetidas ao cruzamento com diferentes planos de informação: declividade, edafologia, hidrografia e disponibilidade viária. Com isso, elaborou-se uma coleção de mapas temáticos, fornecendo-se subsídios para a avaliação da situação dos recursos florestais disponíveis na área de estudo.

\section{MATERIAL E MÉTODOS}

\section{Características gerais da área de estudo}

A região de estudo está delimitada pelas coordenadas W $52^{\circ} 30^{\prime}$ / W $54^{\circ} 00^{\prime}$ e S $30^{\circ} 00^{\prime} / \mathrm{S} 31^{\circ} 00^{\prime}$, que compreende a carta topográfica de Cachoeira do Sul, na escala 1:250.000, folha SH 22-Y-A. Esta abrange as áreas de transição das regiões fisiográficas do Escudo Riograndense e Depressão Central do Estado do Rio Grande do Sul, totalizando 16.124,20 $\mathrm{Km}^{2}$, aproximadamente $5,60 \%$ da área do Estado. A região 
faz parte da Bacia Hidrográfica do Jacuí, onde é banhada pelos Rios Jacuí, ao norte, e Camaquã, ao sul. A economia é baseada no setor primário e se destacam: a agricultura irrigada e de sequeiro, a pecuária extensiva, áreas florestais e extração mineral. Encontram-se, na área de estudo, os solos Podzólicos e secundariamente Brunizén, além dos Planossolos nas planícies aluviais. Conforme BRASIL (1973), as principais unidades de mapeamento são: Rio Pardo, Ibaré, São Jerônimo, Cerrito, Alto das Canas, Seival, Venda Grande, Caldeirão, Vacacaí e Santa Maria. Segundo classificação climática de Köeppen, predomina o clima sub-tropical $c f a$, cuja temperatura média anual é de $19,30^{\circ} \mathrm{C}$, sendo o mês mais quente com $31,5^{\circ} \mathrm{C}$ e o mês mais frio com $9,3^{\circ} \mathrm{C}$. A precipitação média anual é superior a $1.500 \mathrm{~mm}$.

Conforme RADAMBRASIL (1986), a região apresenta uma diversificada cobertura vegetal, onde se encontram áreas de formação pioneira, de tensão ecológica, florestas estacional semidecidual, florestas estacional decidual e áreas de savana.

\section{Materiais}

Os materiais utilizados no trabalho constam de: (a) materiais cartográficos (imagens TM - Thematic Mapper / Landsat 5 / 1995, obtidos junto ao INPE Instituto Nacional de Pesquisas Espaciais; carta topográfica SH 22-Y-A / escala 1: 250.000 do mapeamento sistemático do IBGE - Instituto Brasileiro de Geografia e Estatística; mapeamento de solos / escala 1: 750.000 obtido junto ao Departamento Nacional de Pesquisa Agropecuária) e (b) equipamentos e aplicativos (microcomputadores, mesa digitalizadora, impressoras, veículo, GPS - sistema de posicionamento global e o SIG - sistema de informações geográficas Idrisi for Windows).

\section{Metodologia}

A metodologia empregada para a consecução das atividades propostas foi dividida em: (1) processamento digital; (2) georeferenciamento das imagens; (3) reambulação temática; (4) classificação digital do uso da terra; (5) quantificação do uso da terra; (6) levantamento da base de dados; (7) cruzamento geoespacial das bases temáticas e (8) elaboração de mapas temáticos.

Na primeira etapa, processaram-se digitalmente três bandas espectrais do sensor TM, banda $3(0,63$ $0,69 \mu \mathrm{m})$, banda $4(0,76-0,90 \mu \mathrm{m})$ e banda $5(1,55-1,75 \mu \mathrm{m})$ de intervalo espectral. Estas foram convertidas do arquivo gráfico padrão do Instituto Nacional de Pesquisas Espaciais (.dat) para o formato (.tiff), reconhecido no sistema de informações geográficas utilizado. Após, elaborou-se a composição colorida, processada a partir das bandas 3, 4 e 5 associadas às cores azul, verde e vermelho respectivamente.

Na etapa de georeferenciamento das imagens TM, o objetivo foi referenciá-las geograficamente ao terreno por meio de sua localização espacial, utilizandose para tal, o sistema de coordenadas UTM (Universal Transversa de Mercator). Assim, foi necessário alocar vinte e dois (22) pontos de controle. O valor do número de linhas e colunas da imagem a ser gerada foi calculado a partir da razão entre as coordenadas de máxima e mínima pela resolução da imagem (30 m). Na correção geométrica, utilizou-se o polinômio cúbico.

Após o georeferenciamento, tivemos a etapa de reambulação temática, no qual se fez necessária confirmação a campo dos padrões de resposta espectral da imagem. Foi realizado uma busca e coleta destas informações, utilizando-se a composição colorida, a carta topográfica e o GPS, este utilizado principalmente na confirmação das coordenadas do local amostrado com padrão específico e na orientação e auxílio à sua localização.

Na etapa de classificação temática de uso da terra, optou-se pela classificação digital supervisionada pelo método de máxima verossimilhança, obtida em função do conhecimento prévio de padrões espectrais das áreas amostrais. Isso permitiu a seleção de áreas de treinamento confiáveis, definindo-se que o algoritmo classificador operasse com base na distribuição de probabilidade de cada classe, realizada em função dos temas de interesse: florestas implantadas de Pinus sp. e Eucalyptus sp. , florestas nativas e capoeiras.

A quantificação do uso da terra consistiu em determinar as áreas das diferentes classes obtidas através da função de cálculo de áreas, sendo este efetuado a partir da contagem do número de pixels classificados em cada um dos temas (classes de uso da terra), considerando a resolução espacial de 30 metros.

A etapa de levantamento das bases de dados para a elaboração dos planos de informações foi necessária para processar as informações provenientes da rede viária, rede hidrográfica, altimetria e classes de solos, de forma a compor o banco de dados com informações que descrevem qualitativamente a distribuição espacial dessas bases. As informações inerentes à rede viária, rede hidrográfica e altimetria foram obtidas a partir da digitalização da carta topográfica em questão, já as informações de solo foram digitalizadas a partir do mapeamento de solos. Posteriormente as informações digitalizadas no formato vetorial foram convertidas para o formato raster através do módulo específico do SIG utilizado. Por último, no módulo de cálculo de distância foi mensurado o comprimento da rede viária e hidrográfica; no módulo de cálculo de áreas foi 
quantificada a ocupação das diferentes classes de solo e no módulo de interpolação, as classes de declividade foram geo-espacializadas.

Como última etapa, desenvolveram-se os cruzamentos geoespaciais das bases temáticas, obtidos a partir do estabelecimento de um arquivo de regras no SIG utilizado. Distintas operações matemáticas do tipo booleanas foram efetuadas utilizando-se operadores lógicos, que permitiram realizar cruzamentos entre os diferentes planos de informação.

\section{RESULTADOS E DISCUSSÃO}

Após o processamento digital das imagens e a reambulação, observou-se a faixa de diferenciação da resposta espectral dos temas. Para isso, foi utilizado o número digital (ND), o qual foi calculado a partir da redução das componentes RGB para valores de 256 padrões. Assim, os temas levantados foram divididos em subclasses. A subclasse de uso da terra a1, florestas nativas, secundárias e capoeiras, com ND entre 150 e 162, de dimensões relativamente reduzidas, distribuídas principalmente ao longo da rede de drenagem e encostas. As subclasses a 2 e a3 representaram respectivamente as florestas implantadas de Eucalyptus sp. (ND 158 á 168) e Pinus sp. (ND 155 á 167), que possuem dimensões variáveis, com formato regular e estão relativamente bem distribuídas na área de estudo.

No processo de georeferenciamento, obtiveram-se 22 pontos de controle, sendo o cálculo do número de linhas e colunas da imagem respectivamente 6541 e 5125 , com o erro médio quadrático de 0,002419 unidades de imagem, ou seja, 13,70 metros. Conforme EASTMAN (1994), está dentro do padrão admitido (1/2 da resolução do pixel), que foi $30 \mathrm{~m}$.

Na quantificação do uso da terra, obteve-se na subclasse a1 (Florestas nativas, secundárias e capoeiras) 5.300,94 $\mathrm{Km}^{2}$, perfazendo 32,88 \% da área de estudo; a subclasse a2 (Eucalyptus sp.) foi mensurada em $124,16 \mathrm{Km}^{2}$ e totalizou $0,77 \%$ da área; a subclasse a3 (Pinus sp.) com 305,34 $\mathrm{Km}^{2}$ e representou 1,90\%. Assim, verificou-se a expressiva cobertura florestal na área de estudo, apresentado na figura 1- A.

Na obtenção das bases de dados da carta topográfica para a elaboração dos planos de informações, foi levantado primeiramente o comprimento total da rede de drenagem, incluindo as ravinas, canais e tributários, totalizando $8.295,80 \mathrm{Km}$ de extensão. Da mesma forma, mensuraram-se as rodovias federais, estaduais e municipais em 6.053,00 Km. No que se referem as classes de declividades, estas foram estratificadas em cinco classes: classe 1 ( 0 a12 \%), classe
2 (12 a $30 \%)$, classe 3 (30 a $55 \%$ ), classe 4 (55 a $100 \%)$ e classe 5 (> $100 \%)$. Na base de dados disponível pelo mapa de solos, verificou-se a existência de 20 unidades, sendo que a de maior ocorrência foi a unidade Ibaré, com 2.840,41 $\mathrm{km}^{2}$, perfazendo $17,62 \%$ da área de estudo.

No cruzamento geoespacial do plano de informação da cobertura florestal (figura 1 - A) com o plano de informação das unidades de solo (figura 1 - B), verificou-se a distribuição das áreas florestais dentro de cada unidade de solo. A subclasse a1 (Floresta nativa, secundária e capoeira), teve maior ocorrência na unidade Ibaré, com $1.285,81 \mathrm{~km}^{2}$, eqüivalendo a $25,53 \%$ dessa subclasse. Analisando este dado, pode-se associar estas áreas com a cobertura original da floresta subtropical arbustiva, característica da Serra do Sudeste. Na subclasse a2 (Eucalyptus sp.) verificou-se a maior ocorrência na unidade de solo Vacacaí, com $61,53 \mathrm{~km}^{2}$, representando 50,32\% da subclasse. Este resultado ocorre em função de características do relevo, suavemente ondulado, cuja fertilidade natural é de moderada a forte e onde geralmente encontra-se grande parte da produção agropecuária da região. Assim, temse a ocorrência de povoamentos florestais característicos na forma de talhões de Eucalyptus sp., utilizados na proteção do gado, material combustível para os engenhos de arroz e proteção contra intempéries a áreas construídas. Já a subclasse a3 (Pinus sp.) localiza-se, em sua grande maioria, na unidade Ibaré, com $143,95 \mathrm{~km}^{2}$, equiivalendo a 47,31 \% dessa subclasse. Essa ocorrência é devido ao grande número de povoamentos de Pinus sp. implantados nessa região com objetivo de fornecer madeira a setor da indústria moveleira; verifica-se ainda pelos limiares da classificação digital, que a resposta espectral da vegetação natural de floresta subtropical arbustiva, atinge valores semelhantes (ND 150 á 162) à resposta espectral de bosques recobertos com Pinus sp. (ND 155 á 167), superestimando o recobrimento de Pinus sp.

No cruzamento do plano de informação da faixa de preservação permanente da rede de drenagem, definida pela legislação florestal, com o plano de informação da cobertura florestal da subclasse a1 (Floresta nativa, secundária e capoeira), foi encontrada $143,64 \mathrm{~km}^{2}$ de recobrimento florestal, representando a cobertura de apenas 38,67 \% da área de preservação. Salienta-se a presença de um grande número de áreas com agricultura ou solo preparado para o cultivo de arroz irrigado na faixa de preservação permanente.

No cruzamento do plano de informação da rede viária com o plano de informação da cobertura florestal, verificou-se que ambas subclasses implantadas, a2 (Eucalyptus sp.) e a3 (Pinus sp.), apresentaram sua maior distribuição na distância de até 


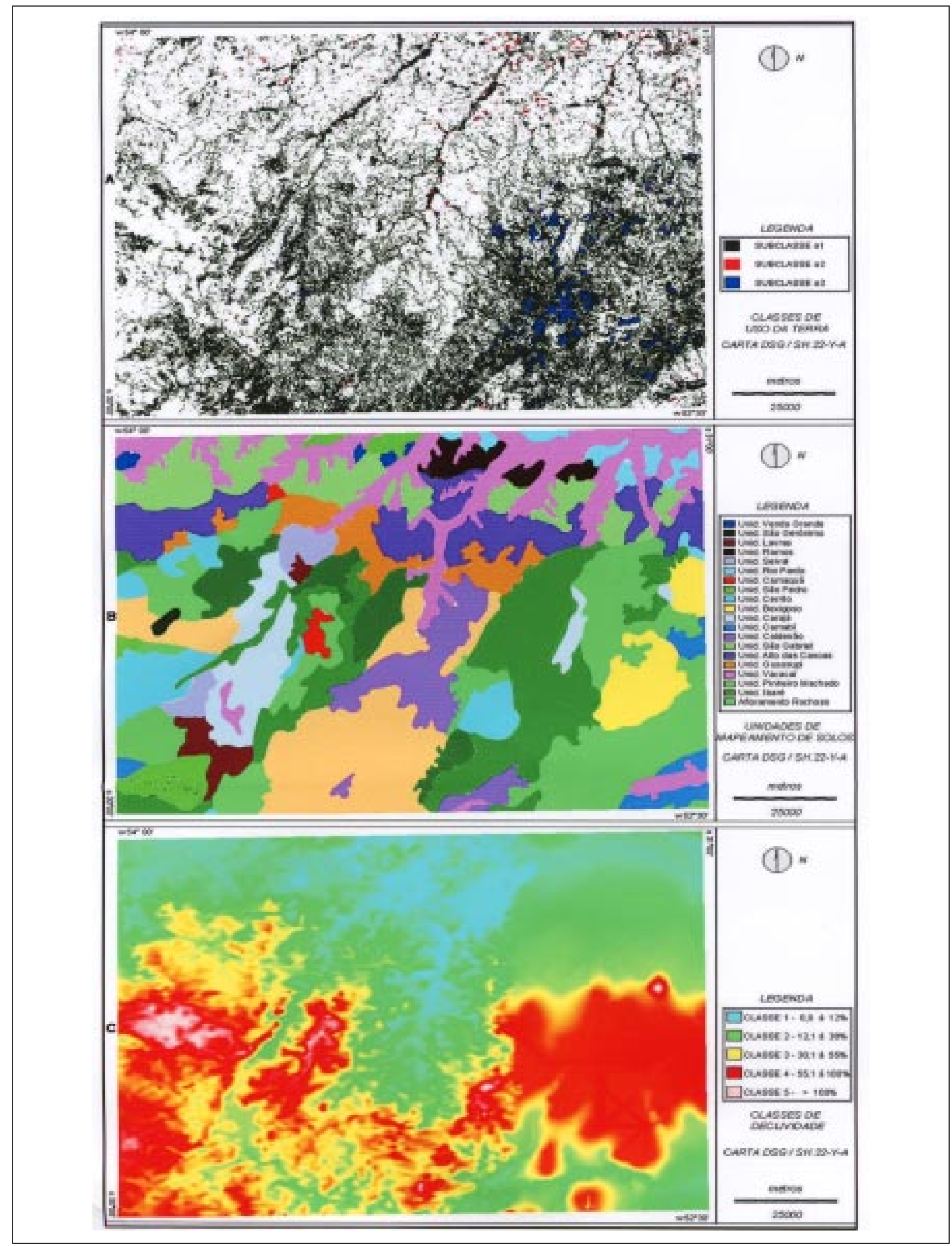

Figura 1 - Planos de informação, sendo: A-classes de usos da terra de cobertura florestal, B- unidades de mapeamento de solos e Cclasses de declividade. 
$1 \mathrm{Km}$ do eixo das estradas, com 55,86 Km² (44,99\%) e $134,91 \mathrm{Km}^{2}(44,19 \%)$ respectivamente. Isto demonstra que, em média, 44,59\% desses povoamentos encontram-se próximas à rede viária, facilitando seu manejo, exploração e transporte, além da sua valorização comercial.

No cruzamento do plano de informação das classes de declividade (Figura 1 - C) com o plano de informação da cobertura florestal (Figura 1 - A), obteve-se a conformação das áreas florestais dentro de cada um dos níveis de declividade. Verificou-se que a subclasse a1 (Floresta nativa, secundária e capoeira) apresentou $1.866,50 \mathrm{~km}^{2}(34,18 \%)$ de sua área na declividade entre 12,1 a $30 \%$. e apenas $168,77 \mathrm{Km}^{2}$ (3,18 \%) em declividade acima de 100,00 \%. Já a subclasse a2 (Eucalyptus sp.), apresentou o maior percentual de cobertura dentro da declividade de 0 a $12 \%, \operatorname{com} 78,04 \mathrm{~km}^{2}(62,85 \%)$. Da mesma forma quando verificado os valores da subclasse a3 (Pinus sp.), detectou-se a maior ocorrência dentro da declividade de 0 a $12 \%$, com 128,96km², eqüivalendo a 42,06\%. Assim, ao analisar estes dados, pôde-se confirmar a presença de grande parcela das florestas implantadas da subclasse a2 e subclasse a3, na classe de declividade de 0 a $12 \%$. Este fato está possivelmente ligado ao sistema de cultivo de áreas florestais característico da região de estudo, nas quais principalmente os povoamentos de Eucalyptus sp. são implantados nas áreas de menores declividades. Essa característica está diretamente vinculada ao sistema de produção agropecuária (arroz irrigado e gado de corte de forma extensiva), sendo implantados diversos povoamentos com objetivo de produção de energia para secagem do arroz, madeira para construções rurais e proteção do gado. Ao analisar a distribuição dos povoamentos de Pinus sp., verifica-se que, apesar de $42,06 \%$, se sua cobertura estar em baixas declividades, temos $57,94 \%$ de ocorrência nas regiões de declividades mais acentuadas, onde os povoamentos foram implantados com objetivo específico de produção de madeira de qualidade para o mercado moveleiro.

Constatou-se ainda que a região de estudo, apesar de possuir áreas de declividade superior a $100 \%$ $\left(45^{\circ}\right)$, onde deveria haver recobrimento florestal segundo legislação vigente, apresentou somente 53,06 \% de áreas recobertas por florestas. Esse fato possivelmente devese a dois motivos: primeiro, a eliminação da cobertura florestal natural (floresta subtropical) das encostas para cultivos agrícolas de sequeiro e formação de pastagens para a bovinocultura extensiva, e o segundo, algumas áreas da região da serra do sudeste apresentam em sua formação original, locais de campo e campo sujo localizados em áreas de encostas.

\section{CONCLUSÕES}

O processo de georeferenciamento utilizando, polinômio cúbico, apresentou precisão dentro da escala trabalhada, sendo o Erro Médio Quadrático(EQM) de 13,70m.

A subclasse a1 (Floresta nativa, secundária e capoeira) apresentou o maior índice de cobertura florestal da área de estudo, com 32, $88 \%$.

A subclasse a1 (Floresta nativa, secundária e capoeira) e a subclasse a3 (Pinus sp.), tiveram a maior ocorrência na unidade de solo Ibaré, com 25,53 \% e 47,31 \% respectivamente; já a subclasse a2 (Eucalyptus sp.) teve maior significado na unidade Vacacaí com 50,32\%.

Existe baixa ocorrência de cobertura florestal (subclasse a1) nas áreas de preservação permanente, sendo que essas áreas apresentam somente $38,67 \%$ de recobrimento.

Os povoamentos florestais implantados localizam-se em até $1 \mathrm{~km}$ de distância em relação ao acesso em rede viária em 44,59 \% de sua totalidade.

As áreas de florestas implantadas das subclasses a2 e a3, localizam-se, em sua expressiva maioria, nas declividades de até $12 \%$.

Recomenda-se aplicar a metodologia proposta em levantamentos semelhantes e ocasiões distintas de monitoramento ambiental e ocupação agrosilvipastoris.

\section{REFERÊNCIAS BIBLIOGRÁFICAS}

ASRAR, G. Theory and applications of optical remote sensing. New York : Wiley, 1989. 734p.

ASSAD, E.D.; SANO, E.E. Sistema de informações geográficas: aplicações na agricultura. 2.ed. Brasília : EMBRAPA, 1998. 434p.

BRASIL. Código florestal brasileiro, Lei $n^{\circ} 4.771$. Brasília, 1965. 5p.

BRASIL. Levantamento de reconhecimento dos solos do estado do Rio Grande do Sul. Recife : Departamento Nacional de Pesquisa Agropecuária, 1973. p.159-269.

BURROUGH, P.A. Principles of geographical information systems for land resources assessment. Oxford : Clarendon, 1989. 194p.

DUTRA, L.V.; SOUZA, R.C.M. de; MOREIRA, J.C. Análise automática de imagens multiespectrais. São Paulo : INPE, 1981. 139 p.

EASTMAN, J.R. Idrisi: exercícios tutorais. Porto Alegre : UFRGS, 1994. 109p.

NOVO, E.M.L. Sensoriamento remoto, princípios e aplicações. São Paulo : Blucher, 1992. 308p. 
PEREIRA, R.S. Sistema de tratamento de imagens multiespectrais. 1995. 262f. Tese (Doutorado) - Curso de Pósgraduação em Eng. Florestal, Universidade Federal do Paraná.

RADAMBRASIL. Levantamento de recursos naturais. Rio de Janeiro : IBGE, 1986. p.313-352, 353-383, 405-484, 541-581.
SILVA, E.M. et al. Pesquisa operacional: programação linear, simulação. 3 ed. São Paulo : Atlas, 1998. 184p.

TEIXEIRA, A. L. de A.; MORETI, E.; CHRISTOFOLETTI, A. Introdução aos sistemas de informações geográficas. Rio Claro : Do Autor, 1997. 80p. 